\title{
Fobia de Estado e a Resistência ao Recolhimento Compulsório de Bebês
}

\section{State Phobia and Resistance to Compulsory Baby Gathering}

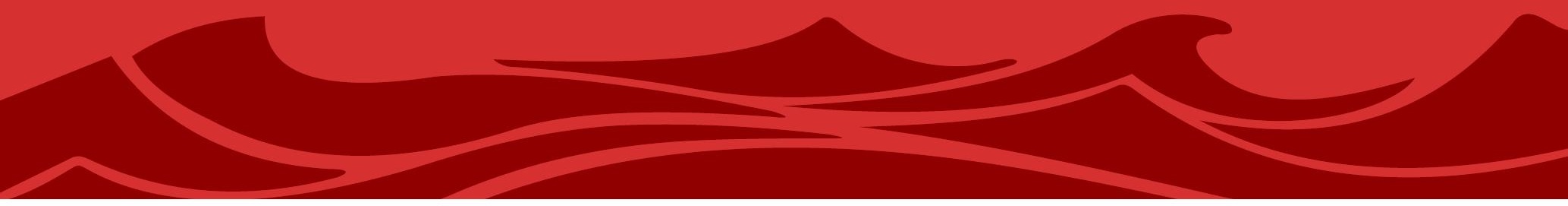

\section{Túlio Batista Franco}

Departamento de Planejamento em Saúde. Universidade Federal Fluminense.

Email:tuliofranco@gmail.com
"A justiça não existe! Direitos Humanos não existem! O que importa é a jurisprudência".

(Deleuze) $^{1}$

\section{Resumo}

Este artigo se propõe denunciar o recolhimento compulsório de bebês, como dispositivo da governamentalidade atual e propõe a resistência a partir de dois conceitos: "Fobia de Estado" e "Governamentalidade Reversa" de Foucault, que são discutidos ao longo do texto. A partir de recomendações do Ministério Público de Minas Gerais e decisões do Juizado da Infância e Juventude em Belo Horizonte, a partir de 2014, a rede de maternidades do SUS vem informando ao sistema judiciário, a frequência de gestantes que usam ou usaram drogas. Diante de tal informação têm sido expedidas ordens de recolhimento compulsório dos bebês filhos destas mulheres que são abrigados em instituições públicas para posterior adoção. Se organizou uma resistência a estas ações, que retomam o tema do direito das mulheres a terem um tratamento digno, constituírem família com seus filhos e acesso a cuidados da rede pública de saúde, assim como o direito garantido pelo Estatuto da Criança e do Adolescente aos bebês, para que convivam com suas mães e famílias. $O$ artigo discute esta resistência a partir do conceito de "Fobia de Estado" que, segundo Foucault, significa um "Antiestatismo", uma forma de resistir à grandeza que o Estado tem assumido para o exercício do biopoder. Ao final expõe-se o conceito de "governamentalidade reversa", a qual organiza novos dispositivos ligados à ideia 
de governo de si, insubmissão e rebeldia aos modos disciplinares do Estado. Significa a resistência a esta governamentalidade que produz sofrimento, dor e tristeza, como o caso do recolhimento compulsório de bebês.

Palavras-chave: Saúde da criança; Cuidado; Direitos humanos.

\section{Abstract}

This article proposes to denounce the compulsory collection of babies, as a device of current governmentality, and proposes resistance from two concepts: Foucault's "State Phobia" and "Reverse Governmentality", which are discussed throughout the ceiling. Based on recommendations from the Minas Gerais Public Prosecutor's Office and decisions of the Juvenile and Youth Court in Belo Horizonte, from 2014 the network of maternity hospitals of the SUS has informed the judicial system about the frequency of pregnant women using or using drugs. Faced with such information,

\section{Introdução}

\begin{abstract}
"A mulher vinha correndo no corredor do hospital, gritando aterrorizada pelo filho, com os seios à mostra jorrando leite. Haviam Ihe tirado o bebê do colo, enquanto ela o amamentava. Um agente da polícia o levou por ordem judicial". (Narrativa de fato ocorrido em $\mathrm{BH} / \mathrm{MG}$ ).
\end{abstract}

O texto em epígrafe foi narrado em encontro realizado no Rio de Janeiro no qual se discutiu o recolhimento compulsório de bebês em Belo Horizonte e outros municípios. É o fragmento do que tem vivido e sofrido centenas de mulheres, gestantes, que procuram maternidades da rede pública de saúde, e são surpreendidas com a obrigatoriedade de registro quanto ao suposto hábito de usar drogas. A positividade desta informação é o gatilho para o disparo de um fluxo de ações que orders have been issued for the compulsory collection of the children of these women, who are housed in public institutions for later adoption. A resistance to these actions has been organized, retaking the issue of women's rights and having a dignified treatment, constituting a family with their children, and access to public health care, as well as the law guaranteed by the Child and Adolescent Statute to the babies, so that they live with their mothers and families. The article discusses this resistance from the concept of "State phobia" that according to Foucault means "anti-static", a way of resisting the greatness that the state has assumed for the exercise of biopower. At the end, the concept of "reverse governmentality" is exposed, which organizes new devices linked to the idea of selfgovernment, insubmit and rebellion to the disciplinary modes of the State. It means resistance to this governmentality that produces suffering, pain and sadness, as the case of compulsory recollection of babies.

Keywords: Child health; Care; Human rights.

resultam em intenso sofrimento, horror e crueldade com puérperas e recém-nascidos, motivados pela separação entre ambos. Além do drama social e afetivo sofrido por estas mulheres e suas famílias, incluindo os bebês, esta questão se trata de uma clara violação de direitos. Como se deu esta história?

Em meados de 2014 o Ministério Público de Minas Gerais (MPMG) publica duas recomendações 05 e 6/2014, que orientam os serviços de saúde de que a mãe usuária de drogas que venha a ter seu bebê em maternidades da rede pública, deveria ter tais fatos "comunicados à Vara da Infância e Juventude de Belo Horizonte para decisão 
sobre o acolhimento ou entrega do(a) Recém Nascido (a) à família de origem ou extensa". As recomendações definem um rito sumário para o recolhimento desses recém-nascidos, no entanto, o que as mulheres narram foge de qualquer relação de respeito a direitos, dignidade e humanidade. As recomendações com o aval do Juizado da Infância de Juventude abriram um período de arbítrio em relação ao abrigamento compulsório de bebês, retirada de guarda de filhos das suas mães e adoção das crianças com opinião contrária das mães e seus familiares. Tudo isto está suficientemente documentado e disponível através do blog https://dequemeestebebe.wordpress.com/, dispositivo organizado para denunciar estes fatos e reivindicar que as mães fiquem com seus bebês.

As resoluções mencionadas acima foram o impulso inicial dado pelo MPMG, e motivou o Juizado da Vara Cível da Infância e Juventude de Belo Horizonte, a editar normas como a que pode servista a seguir:

Art. 10. Quando, durante o atendimento médicohospitalar de gestante, parturiente ou puérpera, houver constatação ou ponderadas evidências de que qualquer dos genitores e/ou a criança recémnascida se encontram em situação de grave risco, inclusive em virtude de dependência química ou de trajetória de rua, o profissional de saúde e/ou a instituição hospitalar deverão comunicar o fato ao Juízo de Direito da Vara Cível da Infância e da Juventude da Comarca de Belo Horizonte encaminhando os documentos pertinentes. ${ }^{2}$

A documentação emitida pelos órgãos do judiciário se transformou em dispositivos de criminalização de mães que supostamente usam drogas, condenando-as e a seus filhos recémnascidos a uma vida inteira sem a desejável convivência entre eles. Nega o problema real, de que o uso de drogas e todo processo de maternidade, mesmo sob risco, tratam-se de questões do âmbito da saúde pública. Sendo assim, estas mulheres e seus bebês necessitam de cuidados e uma rede de proteção para seu pleno desenvolvimento. A criminalização como tem sido feita, amplia o problema atual, sem oferecer uma solução eficaz.

Há uma importante mobilização de pessoas, coletivos e movimentos sociais em torno da questão, lutando pela garantia do direito de mulheres de formarem suas famílias e das crianças de terem o convívio com suas mães. Para se defenderem as mulheres começam a negar informações de que estão grávidas e, assim, impossibilitam que a rede pública de saúde realize os cuidados necessários à gestante.

\footnotetext{
E as recomendações do MP se refletiram nas ruas. É o que revela Arnor Trindade, crítico da decisão do MP e referência da Coordenação de Saúde Mental da SMSA. Para o especialista, a possibilidade da retirada das crianças das mães tem coagido muitas a revelarem que estão grávidas. Trindade entende que apartar os bebês de suas mães é uma prática que deve ser revista. $\mathrm{O}$ Estatuto da Criança e do Adolescente diz, em seu primeiro item, que a criança tem o direito de permanecer com a família. ${ }^{3: 1}$
}

O próprio Estatuto da Criança e Adolescente é paradoxal quando menciona a questão, segundo Martins, ${ }^{3}$ o mesmo texto que define que as crianças devem ficar com suas famílias, 
dá margem a entendimento contrário disto quando se trata de mãe usuária de drogas. A jurisprudência é o que passa a definir o direito e, sendo assim, prevalece a interpretação do juiz da vez.

Mas o Ministério Público dá primazia ao trecho que diz que a criança deve crescer em ambiente longe de usuários de entorpecentes. Às vezes, é possível que a mãe se recupere e que a criança fique sob guarda da família extensa.

Toda atividade do sistema judiciário em colaboração com o Ministério Público Estadual, no caso do abrigamento compulsório de bebês, em primeiro lugar, tem um sentido discriminatório, porque é direcionada a mulheres pobres. As resoluções foram dirigidas especificamente às maternidades públicas, toma como alvo as mulheres que são dependentes do serviço público de saúde, ou seja, as de maior vulnerabilidade socioeconômica. Em segundo lugar, mostra total insensibilidade ao não perceber o outro, uma criança recém-nascida e sua mãe, como portadores de necessidades de cuidados, em uma fase particularmente sensível e importante das suas vidas. As normas editadas pelo Ministério Público Estadual e o Juizado são, por si, um ato de extrema violência que, ao contrário de proteger, vulnerabilizam as mães e seus bebês, ou seja, os tornam mais vulneráveis por não ofertarem opções de cuidado. Expõe a criança ao abandono ao colocá-la em abrigamento compulsório e subjuga a mãe à condição de "órfã do seu próprio filho", ao qual não tem a possibilidade de convivência. Em terceiro lugar, toda esta atividade do sistema judiciário demonstra a total banalização do sofrimento alheio, ou seja, há uma naturalização do sofrimento do outro. As inúmeras possibilidades de cuidado são simplesmente negadas, dando lugar a uma suposta moral, que, através do biopoder atribuído aos órgãos judiciais, impõe uma punição a mães e seus filhos.

O poder coercitivo do Estado e a sanha por punições que agenciam a ação dos órgãos judiciais, faz com que estes imponham uma grave afronta ao direito à maternidade, desrespeitando o Estatuto da Criança e Adolescente (ECA) ao arrancar a crianças do convívio com a mães a partir do abrigamento compulsório. Toda atividade oriunda das recomendações do MPMG e do juizado podem ser classificadas como violência de estado contra estas pessoas, mães e bebês.

Trabalhadores das maternidades públicas têm sido pressionados pelo MPMG para que informem aos órgãos do judiciário da presença de gestante/puérpera, usuária de drogas. Esta comunicação é o ato formal de denúncia, que abre a possibilidade de ação do judiciário e coloca estas mães à mercê da justiça, subjugando-as às normas já emitidas de condutas para o recolhimento compulsório dos seus bebês.

Acontece que estas mães vivem uma "transformação incorpórea": "A transformação 
incorpórea é reconhecida por sua instantaneidade, por sua imediatidade, pela simultaneidade do enunciado que a exprime e do efeito que ela produz", "14 é a transformação instantânea dos corpos, dada por uma "palavra de ordem", que gera efeitos imediatos. Por exemplo, a mulher, gestante, mãe, passa da condição de puérpera para a de "usuária de drogas", cujo efeito imediato é deixar de ser uma pessoa portadora de cuidados e proteção à sua saúde, para alguém que cometeu "crime" ou "pecado" e, portanto, merecedora de punição ou penitência.

A denúncia de uma mãe pelo uso de drogas para que seu bebê seja recolhido a um abrigo, seria como se estas mães passassem aos olhos destes trabalhadores por esta "transformação incorpórea" e, eles mesmos, deixassem de ser cuidadores para serem denunciadores, passando da condição de agentes do serviço público de saúde para agentes do sistema judiciário. A transformação incorpórea modifica o seu status social e afetivo: de mães, filhos e trabalhadores da saúde.

Há um processo de subjetivação em curso que faz com que as pessoas, em geral, que aderem às teses do MPMG e do Juizado da Infância e Juventude façam a inversão dos papéis dos trabalhadores e da rede pública de saúde, e os transformam de uma missão atual de cuidadores, com atribuição de zelar pela saúde e bem estar das mães e seus filhos, para denunciantes das mesmas aos que seriam aos olhos delas, seus algozes. Essa nova subjetividade denuncista e punitiva vem dominando a cena de cuidados em muitos lugares. A resistência a este estado de coisa deve se dar também pela construção de um novo território subjetivo em que sejam invertidos os valores dominantes atuais, se estes perseveram no dano às crianças e suas mães, impedindo-as de conviverem por toda uma vida. Isto tem sido irreversível e fatalmente muito cruel, pois as adoções destas crianças são feitas à revelia e contra a opinião das mães e suas famílias.

Em janeiro de 2015, o Conselho Municipal de Saúde de Belo Horizonte aprovou resolução na qual recomenda que os trabalhadores do SUSBH não precisam informar e encaminhar casos de gestantes usuárias de drogas à Vara da Infância e da Juventude, conforme recomendado pelo Ministério Público de Minas Gerais (MPMG) desde junho de 2014. Com isto os trabalhadores não ficam obrigados mais a fazer estas denúncias como anteriormente. Sem dúvida uma vitória da mobilização que se verifica na sociedade, de resistência ao recolhimento compulsório de bebês.

Tomando como fontes deste trabalho as matérias publicadas na imprensa mineira entre os anos de 2014 e 2017 e as narrativas dos que têm se apresentado em reuniões, fóruns e encontros que discutem o tema, podemos inferir que o fluxo que leva ao recolhimento compulsório funciona, de modo geral, da seguinte forma: uma gestante ao dar entrada no plantão de algum hospital público é 
orientada a preencher um cadastro, no qual consta a pergunta se a mesma é ou foi usuária de drogas. Se a resposta for positiva o estabelecimento deve informar ao juizado da Infância e Juventude da Comarca de Belo Horizonte, que deverá decidir pelo recolhimento compulsório do bebê a uma instituição pública, a fim de que seja disponibilizado para adoção. Este abrigamento do recém-nascido acontece por força de decisão judicial tomando, de forma absolutamente precária, os argumentos da mãe e da sua própria família. Nota-se que a mãe e sua família não são consideradas, é como se o enredo de cada história de mãe e seus bebês já estivesse previamente escrito, pois prevalece sempre a narrativa segundo a qual "a prioridade é a criança", repetido como um mantra por todos os agentes do Estado, e com este "script" simplesmente se atropela o direito da mãe e da criança de serem uma família e terem entre si a necessária convivência. Tomando por referência este fluxo básico aqui descrito há variações de muitos tipos, geralmente relatando tragédias pessoais com danos físicos e afetivos que marcam as vidas de mães e filhos por toda uma vida. Como pode-se ver no caso de Aline:

Assim que nós (mães) recebemos alta da maternidade (após o parto), fomos orientadas por uma funcionária da Santa Casa e fomos de ambulância até a sede do Ministério Público. Fui informada de que o juiz me faria apenas algumas perguntas. Porém, quando cheguei lá, um homem me falou 'moça, se você não entregar seu filho, nós vamos machucá-lo, porque a gente vai tirá-lo de você de qualquer jeito'", contou Aline Paula Oliveira, artista plástica e estudante de direito, que teve seu filho recolhido pela Justiça há seis anos.
Aline afirmou que o seu processo, como muitos outros, foi feito de forma arbitrária, uma vez que ela fazia uso moderado da droga e que a criança estava bem e saudável. A mãe garantiu que fez o tratamento completo de reabilitação e recebeu liberação médica. Ainda assim, não consegue autorização para estar com seu filho. "Desde o momento da retirada eu tenho lutado por ele. A luta é para conviver. Não vou tirá-lo da sua nova família, mas quero que seja garantido o direito dele saber que não foi abandonado pela mãe, que não foi rejeitado. Que ele saiba que ele tem uma irmã linda, que ele possa conhecê-la, desabafou. (Câmara Municipal de Belo Horizonte, $17 / 3 / 2017){ }^{5}$

Vemos aqui a expressão dramática de até onde vão os efeitos da ação movida por um Ministério Público persecutório e um judiciário instrumentalizado por uma jurisprudência produzida por ele mesmo. Eles negam ou desconhecem aspectos técnicos quanto à possibilidade de cuidados a estas mães, humanitários envolvendo uma questão como a maternidade, seres, famílias.

É como se forças estranhas e hostis se movessem contra o imaginado caminho ascendente do nosso marco civilizatório, construído a partir da "Constituição Cidadã" de 1988 e das leis complementares que fundaram o direito da criança e do adolescente através do Estatuto da Criança e do Adolescente, do acesso universal à saúde através do Sistema Único de Saúde, a Assistência Social e o direito à Educação. Este movimento constituinte de um ordenamento societário que objetiva aos direitos sociais como fundamentais, vem sendo violentamente interditado no atual momento, onde o recolhimento compulsório de bebês é a ponta do iceberg e um analisador potente para 
revelar o quanto as pessoas têm sido violentadas no seu direito e na sua humanidade.

Enquanto pensamos ou, pelo menos, lutamos para que as políticas sejam cada vez mais generosas com as pessoas, que o cuidado seja atribuição de todos, uns com os outros, nos deparamos com intervenções deste tipo. Fomos atrás das respostas às questões que se colocaram frente a todos estes acontecimentos. A compreensão dos acontecimentos não é apenas uma racionalidade normativa, é preciso que as narrativas sejam incorporadas, se colocando em contato com o circuito dos afetos presentes neste acontecimento. Assim, talvez seria possível criar a implicação suficiente para conhecer o que acontece, perceber o outro como expressão de desejos violentados, necessidades não atendidas, apoios precários da institucionalidade presente nos cenários de cuidado às gestantes.

\section{A potência do afeto para o cuidado}

\section{"Minha filha devolveu minha vida"}

A frase acima é parte da narrativa de uma mãe, residente no Ceará, com filha recém-nascida, ex-usuária de drogas. Esta mulher participou da pesquisa "Rede de Avaliação Compartilhada" que, em Fortaleza, teve como tema de estudo a Rede Cegonha, de cuidado materno infantil. ${ }^{6}$ De forma resumida podemos dizer que esta mãe deixou de usar drogas no início da gestação, e permaneceu assim após o nascimento da filha.
Construiu com o bebê um forte vínculo, reconstituiu as relações afetivas rompidas anteriormente, refez suas fontes de alegria, não dependendo mais das drogas para ter prazer e retomou assim um novo projeto de vida.

A pesquisa traz a evidência de que é possível contar com a maternidade como fonte de potência para o cuidado de si, abrindo a possibilidade de pactuação com a vida, deixando as mães o uso de drogas para cuidar dos seus bebês. O filho ou filha é um dispositivo de cuidado, esta é a questão fundamental que foge à compreensão dos órgãos judiciários. Ao invés de usar esta ferramenta sócio-afetiva para superação dos problemas decorrentes do uso abusivo de drogas associado à maternidade, a ação atual do judiciário, tal como se configura, joga por terra esta oportunidade.

O caso descrito acima pega como centro a questão da força dos afetos no processo de subjetivação, ou seja, produção de novas subjetividades. Tal princípio pode ser sustentado com base na ideia de Spinoza (2009), ${ }^{7}$ segundo a qual, os corpos quando se encontram têm uma capacidade de afetar uns aos outros. Estes afetos produzem efeitos no outro, que podem ser a expressão de alegria e, neste caso aumenta a sua potência de agir no mundo, ou tristeza, quando esta potência é diminuída. No encontro, ainda segundo o filósofo, se forma um "campo de consistência" entre os corpos através do qual os afetos são transmitidos por intensidades, isto é, imperceptíveis no plano da razão, mas com alta 
potência na reconfiguração dos corpos e vidas que são afetados.

O que se observa é que a maternidade reconfigurou a forma como esta gestante significa o fato de ser mãe, de ter um ser sob seus cuidados, a filha. $\mathrm{O}$ encontro com o bebê no seu nascimento representa o fechamento de tudo isto. Isto tudo por efeito dos afetos que a maternidade provocou nela mesma. Vemos, portanto, a força terapêutica dos encontros, dos afetos e o quanto eles têm uma capacidade operatória sobre a realidade em si, no outro e no mundo.

No texto "Em Busca da Clínica dos Afetos", Franco e Galavote ${ }^{8}$ discutem a partir do "Caso $J R^{\prime \prime}$ a grande capacidade de reação e ação de um corpo na produção de vida em si mesmo. Ação neste caso, como potência revigorada a partir de novos encontros que produziram no usuário uma enorme capacidade de agir. Só uma subjetividade ativada pelo desejo de produzir vida é capaz de uma reação à adversidade que a existência em certos cenários produz nas pessoas. Este estudo vai demonstrar que não há um "corpo frágil", pois cada um tem sua potência, e cabe a um projeto terapêutico atuar para ativar esta potência que está no plano da subjetividade e no núcleo de desejo.

O desejo atua como uma força propulsora que nos coloca em movimento para construir projetos de vida, produzir novos modos de existir no mundo, reconfigurar os cenários no qual se vive. Ele é sempre um agenciamento, energia vibrante, capaz de romper obstáculos, fazer desvios, encontrar fissuras nos espaços institucionais para construir possibilidades que antecipem novos mundos, façam novas existências tomarem formas, enfim, produzir uma nova construção de si e do mundo.

O que estes estudos nos informam, com muita evidência, sustentados na produção do cotidiano, é que a maternidade, assim como um encontro que se revela um importante acontecimento na vida de uma pessoa, tem uma enorme potência terapêutica. A maternidade pode fazer com que as mães, antes usuárias de drogas, repactuem consigo mesmas a sua existência, passando ao cuidado de si, assim como ao cuidado do filho recém-nascido.

Tomando por estas evidências aqui demonstradas, a ação do MPMG assim como do Judiciário no caso do recolhimento compulsório, além de uma arbitrariedade jurídica, é um enorme erro do ponto de vista terapêutico, do cuidado que se deve ter com as mães usuárias de drogas, que são o tema desta discussão. Tirar estas crianças das suas mães é o mesmo que condená-las a uma culpa infinita com a qual terão que conviver por toda sua vida, aprofundando o abismo existencial no qual vivem e, mais do que isto, retira delas a mais potente terapêutica que já tiveram a oportunidade de ter, que é a possibilidade criada a partir encontro com seus próprios filhos.

O que fica evidente é que o MPMG e o judiciário 
não se importam com estas vidas, sequer pensam que o uso de drogas neste caso é um problema de saúde, e que estas mães têm direito a uma possibilidade de cuidado, que as ajude a retomar sua vida com seus bebês. Afirmamos com toda veemência que estamos diante de um caso de saúde, que deve, portanto, ser conduzido como tal, com as ferramentas próprias do cuidado. E que os órgãos do sistema judiciário negam este direito a estas mães e seus filhos recém-nascidos, tratando apenas como um problema judicial e impondo medidas coercitivas, sob o falso pretexto, ao nosso ver, de proteção dos bebês. Não se protege uma criança subtraindo-lhe o afeto da mãe por toda uma vida. A ação do judiciário produz uma barbárie.

\section{Fobia de Estado e a Resistência}

Deus sabe quanto eu temo a destruição do mundo pela bomba atômica; mas há pelo menos uma coisa que temo tanto quanto esta, que é a invasão da humanidade pelo Estado. 9:103

A intervenção do sistema judiciário à política de cuidado materno-infantil, interditando a possibilidade de mulheres serem mães de seus bebês, e destes serem filhos das suas mães, porque estas são supostamente usuárias de drogas, é um analisador da força coercitiva do Estado quando ele atua no plano da micropolítica. Toma o cotidiano como plano de ação para operar sob o regime disciplinar, regulando os corpos de mulheres, controlando seus afetos, produzindo tristeza e subserviência e punição aos que não "cumprem as regras" de um biopoder ${ }^{9}$ auto atribuído.

De forma resumida apresentamos abaixo três linhas de força que atuam como uma das maiores fontes de agressão ao direito e à cidadania de mulheres e crianças vulneradas, acontecido no período recente. Quais sejam:

i) As mulheres e seus recém-nascidos vítimas da agressão institucionalizada e "legalizada" são pobres, vulnerabilizadas e supostamente trazem histórias de abandono e sofrimento.

ii) O Ministério Público Estadual juntamente com o sistema judiciário se aliam para judicializar as vidas de mães e bebês, tomando decisão de recolhimento dos recém-nascidos para o abrigamento compulsório, interditando a tradicional e bem sucedida política de cuidados materno-infantis. Nega o direito e o cuidado às mães de terem seus filhos e das crianças do convívio com suas famílias.

iii) A denúncia feita por trabalhadores de saúde, mesmo que sob pressão do judiciário, que oferecem denúncia ao Ministério Público e ao juizado da infância e juventude dos casos de mães que supostamente são usuárias de drogas, é parte da trama para o "sequestro de bebês" de suas mães.

Vemos que a ação do estado neste episódio está 
instrumentalizada pelo direito na interpretação do MPMG e do Juizado da Infância e Juventude. A sua atividade é muito mais ampla do que meramente a aplicação do direito, segundo sua intepretação, mas ela propaga uma narrativa segundo a qual defende o direito das crianças. Um sofisma para consolidar a posição de "sequestro das crianças" de suas mães, pois tiraIhes o direito de convivência familiar. Isto polariza certos setores sociais. Estamos diante de um processo complexo que envolve tecnologias de governo, que tem por objetivo o controle dos corpos e a prescrição sobre os modos de vida, entendendo o Estado como um sistema complexo de exercício de poder sobre a população, onde os principais instrumentos estão no saber da economia política e dispositivos de segurança, a governamentalidade, a qual Foucault ${ }^{10}$ entende por:

[...] o conjunto constituído pelas instituições, os procedimentos, análises e reflexões, os cálculos e as táticas que permitem exercer essa forma bem específica, embora muito complexa, de poder que tem por alvo principal a população, por principal forma de saber a economia política e por instrumento técnico essencial os dispositivos de segurança. Em segundo lugar, por 'governamentalidade' entendo a tendência, a linha de força que, em todo o Ocidente não parou de conduzir, e desde há muito, para a preeminência desse tipo de poder que podemos chamar de 'governo' sobre os outros - soberania, disciplina e que trouxe, por um lado, o desenvolvimento de toda uma série de aparelhos específicos de governo [e, por outro lado], o desenvolvimento de toda uma série de saberes. ${ }^{10: 143-144}$

Vemos aqui o alcance do Estado nas suas técnicas de governar a população, contando a regulação da vida através dos saberes e dispositivos disciplinares sobre os modos de vida. Através da governamentalidade é possível formar o entendimento da força que exerce o Estado no plano da micropolítica, de regulação do cotidiano e coerção sobre os modos de vida não convencionais, que operam na diferença ou prescritos pela moral e poder vigentes.

No ano de 2014 em Belo Horizonte os números de recolhimento compulsório de crianças aumentaram de forma significativa. Reproduzo abaixo fragmento de matéria publicada pelo jornal "O Tempo", para dar uma dimensão do que se viveu no ano de 2014 e que se prolonga até hoje:

Da barriga da mãe direto para o abrigo. Esse tem sido o destino de bebês de mães usuárias de crack. De janeiro a outubro, dos 232 novos acolhimentos de crianças de 0 a 2 anos de Belo Horizonte, 158 (68\%) foram em decorrência da droga. ${ }^{11}$

Deste período até os dias atuais o problema vem se agravando e narrativas pronunciadas em encontros e seminários para discutir a questão informam que em julho de 2017 havia registro de que 359 bebês foram retirados de maternidades do Sistema Único de Saúde em Belo Horizonte, de 2014 até esta data, e entregues a instituições para abrigamento compulsório e adoção.

Se produz um verdadeiro "holocausto 2.0", adaptado ao século XXI, em que a morte se faz pelo esmagamento do desejo, a produção intensiva de tristezas nas pessoas, que as tornam menos potentes para a vida, menos ativas na produção de si e mais adaptadas a se resignar a este estado de coisas, ao invés de revoltar-se 
contra ele, a subserviência involuntária. As ações do sistema judiciário promovem um morticínio afetivo, fabricando mães culpabilizadas, tristes, de baixa potência e, por outro lado, crianças abandonadas, institucionalizadas, disciplinalizadas, um mundo afetivo destruído pela brutal e indevida interferência do biopoder judiciário sobre estas vidas, que precisariam, sobretudo, de cuidados, redes de proteção, acolhimento social e afetividade.

O "holocausto 2.0 " que vivemos nos tempos atuais nos remete à ideia de "Fobia de Estado" . Este conceito é atribuído ao extenso crescimento do Estado e à capacidade de se encontrar presente em todo segmento da vida, todos os lugares, em uma atuação que mistura um simulacro de paternalismo com elementos microfascistas. Um Estado que toma corpo, musculatura e perde a sutileza quando se trata de regular os modos de vida e exercer o poder para o controle dos corpos, desativando-Ihes toda energia desejante que seria capaz de produzir novas possibilidades e invenções para a vida.

[...] a ideia de que o Estado possui em si e por seu dinamismo próprio uma espécie de força de expansão, uma tendência intrínseca a crescer, um imperialismo endógeno que o leva sem cessar a ganhar em superfície, em extensão, em profundidade, em fineza, tanto e de tal modo que ele chegaria a se encarregar totalmente do que constituiria para ele ao mesmo tempo seu outro, seu exterior, seu alvo e seu objeto, a saber: a sociedade civil.

O primeiro elemento que me parece de fato percorrer toda a temática geral da fobia do Estado é, portanto, essa força intrínseca do Estado em relação ao seu objeto-alvo, que seria a sociedade civil.:259
Entende-se que o Estado como organismo que detém uma força intrínseca de controle, que exerce uma expansão sem fim sobre a sociedade civil, tomando suas entranhas, contém todos elementos que por si só lhe dão o atributo de poder sobre o outro e a capacidade de produzir a política de controle, regulação e interdição. Sendo assim, ainda segundo o autor, há uma implicação entre as diferentes formas de Estado, seja o Estado administrativo, providência, burocrático, fascista, totalitário, enfim, são todos filhos da mesma raiz, detém características intrínsecas que os tornam similares no modo de atuar sobre o governo da população.

Fobia do Estado não está associado ao tema do "medo", é um conceito que diz respeito ao "antiestatismo", à ideia de resistência à penetração dos dispositivos estatais de controle na microgestão da vida, em ação micropolítica sobre a regulação do cotidiano, no controle dos corpos, na prescrição sobre os modos de vida, enfim, o exercício intenso de biopoder. Antiestatismo é linha de fuga. Resistência esta que deveria levar a uma crise de governamentalidade pelo motivo que: “O Estado não é nada mais que o efeito móvel de um regime de governamentalidades múltiplas." ${ }^{\text {9:106 }}$

Caminhando contra o vento: a resistência pela "governamentalidade reversa".

Chamamos de "governamentalidade reversa" a ação de pessoas e coletivos no plano social, que contraria a governamentalidade estatal, que 
tenta controlar e regular as pessoas. Ela parte do desejo por governar a si mesmo, produzindo sua própria vida, é definida por um certo grau de rebeldia ao instituído, operando por linhas instituintes; e tem por objetivo inverter o fluxo dos afetos, de linhas opressoras contra as mães e seus bebês, criando linhas libertárias; contra o abandono opera por solidariedade comunitária; contra a interdição e controle sobre os corpos, opera por pacto do cuidado e suas existências; o cuidado e a proteção estão na origem da "governamentalidade reversa".

De modo concreto, se o poder estatal "tem por alvo principal a população", a "governamentalidade reversa" tem como centro a pessoa, no caso da saúde, o usuário; se ele tem "por principal forma de saber a economia política", aqui o principal dispositivo de saber é o espaço social e a produção afetiva pelo encontro; e s,e por sua vez, o Estado opera "por instrumento técnico essencial os dispositivos de segurança", a "governamentalidade reversa" opera pela produção do comum, como dispositivo de invenção da vida pautada pelo cuidado e proteção.

A governamentalidade tem por objetivo o exercício do "governo sobre os outros soberania, disciplina", e aqui o que sugerimos é o governo dos outros sobre si mesmos, a voz e protagonismos de pessoas e coletivos com referência a suas necessidades, seus desejos e respeitando o modo específico de existência, quando pactuados projetos terapêuticos, que devem ser singulares, ou seja, dirigidos a cada um para contemplar seu modo específico de existir no mundo.

$\mathrm{O}$ que se pretende com um movimento de resistência no caso do recolhimento compulsório de bebês é a produção de liberdade e pactuação das existências, através da construção de redes de cuidado, amparada institucionalmente nas políticas de saúde, assistência social e educação. O Sistema Único de Saúde, o Sistema de Assistência Social, e a Política Nacional de Educação, pela generosidade que têm, são dispositivos institucionais que podem contribuir na produção de redes de apoio, cuidado e proteção suficientes para impedir a judicialização das vidas de crianças recém-nascidas e suas mães. $E$ para isto há no âmbito societário uma multidão, pessoas, coletivos, entidades, que se organizam das formas mais criativas possíveis e usam ferramentas diversas, em espaços diversificados de produção. Estes também agregam potência aos dispositivos de resistência.

A "governamentalidade reversa" se produz, portanto, por um movimento combinado entre as mães e seus bebês, apoiado pela atuação de todos os que estão implicados na defesa da sua integridade cidadã, social e afetiva, com a construção de uma institucionalidade generosa, cuidadora, libertária por meio das políticas sociais.

\section{Considerações Finais}

Há mais de três anos as gestantes pobres, em 
situação de rua, usuárias ou ex-usuárias de drogas vivem a crueldade e brutalidade impetrada pelos órgãos judiciais da infância e juventude de Belo Horizonte e outras capitais do país. Esta ação se abate sobretudo no núcleo da subjetividade destas mães, no desejo e na vontade, dispositivos de produção de vida em si mesmo, no outro e construção cotidiana do mundo no qual se vivem.

Ao invés do reconhecimento de um problema de saúde, o sistema judiciário anuncia a sua criminalização; ao não apontar para uma rede de cuidado às mães e seus bebês, recomendam o recolhimento compulsório; ao invés de proteção produzem abandono, dor e sofrimento. A tudo isto há uma resposta efetiva e afetiva que procura mobilizar coletivos de técnicos do SUS, especialmente os que trabalham com a atenção à saúde materno e infantil; inúmeras entidades da sociedade civil e tudo isto vai amplificando a denúncia e o apelo para o resgate dos valores de cidadania, direitos da mulher e da criança, já completamente esgarçados, e o cuidado à saúde.

Efetivamente há uma resistência a todos estes acontecimentos, que é consistente nas suas propostas de superação do problema. Por exemplo, em 29 de agosto de 2014, portanto no início da ação repressora sobre estas mães e seus filhos, a Comissão Perinatal da Secretaria Municipal de Saúde Belo Horizonte publica Ofício Circular às Maternidades do SUS-BH com Recomendação para abordagem de mães usuárias de álcool e drogas. Neste documento recupera as diretrizes dos cuidados à maternidade e à infância sugerindo uma série de ações, redes de cuidados e proteção, revertendo em termos propositivos as diretrizes oriundas do MPMG e do Judiciário.

Contando com ampla rede de apoio o documento sugere principalmente o seguinte:

Cada caso deve ser avaliado em sua particularidade e elaborada uma proposta de abordagem integral de cuidado, envolvendo em especial a família, a família estendida e outras possibilidades de apoio no território que possam estruturar um projeto terapêutico singular com a abordagem clínica e apoio social de acordo com a necessidade.

A avaliação clínica individualizada é soberana para a orientação e abordagem terapêutica e social. A separação mãe e filho não deve ser efetivada a priori antes de esgotadas todas as possibilidades de apoio intensivo a esta mulher, seu bebê e sua família. ${ }^{12}$

Igualmente relevante é o manifesto publicado em 10 de dezembro de 2014 assinado por inúmeras entidades da sociedade civil, conselhos profissionais e da saúde, no qual reivindicam a efetividade de uma rede de proteção, a descriminalização destas mães e encaminhamento seguro, quando necessário, apoiado em referências intersetoriais.

Que as redes de saúde mental, da mulher e de atenção a criança do estado e municípios sejam acionadas, bem como toda a rede de assistência à saúde e demais políticas setoriais logo que se identifique o abuso de álcool e outras drogas, para que se amenize o impacto criminalizador e excludente das mulheres, pautando em enfrentamentos complexos que deem conta de conciliar os direitos das mulheres e dos recémnascidos. $^{13}$ 
Os movimentos aqui demonstrados, por dentro e fora do Estado, indicam a capacidade de resistir, produzir novas práticas, reorganizar os saberes e os dispositivos de cuidado para superar o que vem sendo proposto até então pelos órgãos judiciais. Seguimos confiantes de que os que sofrem com os atuais dispositivos disciplinares implementados pelo Estado, podem ativar pessoas e coletivos para construir uma "governamentalidade reversa" que produz efeitos contrários nas políticas de controle, que seja expressão do antiestatal na política que vem sendo proposta até então pelo judiciário. As reações que vêm acontecendo desde o início deste processo em 2014, demonstram que é possível produzir uma nova política, que coloque as pessoas sob governo de si mesmas, produzindo vida em redes de cuidado como forma de articulação do comum, com base nos encontros que o próprio trabalho em saúde proporciona.

\section{Referências}

${ }^{1}$ Deleuze G, Parnet C. O Abecedário [Internet]. [citado jun 2018]. Disponível em: http://escolanomade.org/wpcontent/downloads/deleuze-o-abecedario.pdf.

${ }^{2}$ Poder Judiciário. Vara da Infância e Juventude da Comarca de Belo Horizonte. Portaria 03/2016. Foro, Comarca de Belo Horizonte, 2006.

${ }^{3}$ Martins A. Ruas, drogas e maternidade. Revista Vox. 2016;7(78). [citado nov 2017]. Disponível em: http://www.voxobjetiva.com.br/noticia/945/ruas,-drogas-e-maternidade.

${ }^{4}$ Deleuze G, Guattari F. Mil Platôs. São Paulo: Editora 34; 1995. v.2

${ }^{5}$ Câmara Municipal de Belo Horizonte. Mães denunciam recolhimento compulsório de bebês pela Justiça [Internet]. Boletim 17 mar 2017. [citado nov 2017] Disponível em: https://www.cmbh.mg.gov.br/comunica\%C3\%A7\%C3\%A30/ not\%C3\%ADcias/2017/03/m\%C3\%A3es-denunciam-recolhimento-compuls\%C3\%B3rio-de-beb\%C3\%AAs-pelajusti\%C3\%A7a

${ }^{6}$ Carvalho MRR, Franco TB, Jorge MSB. Rede Cegonha desenhada por gestante usuária de drogas: uma produção do cuidado. In: Merhy EE et al. Avaliação Compartilhada do Cuidado em Saúde: surpreendendo o instituído nas redes. Rio de Janeiro: Hexis; 2016.

${ }^{7}$ Spinoza B. Ética. São Paulo : Autêntica; 2009.

${ }^{8}$ Franco TB, Galavote HS. Em Busca da Clínica dos Afetos. In: Franco TB, Ramos VC. Semiótica, afecção \& cuidado em saúde. São Paulo, Hucitec; 2010.

${ }^{9}$ Foucault M. Nascimento da Biopolítica. Martins Fontes: São Paulo, 2008.

${ }^{10}$ Foucault M. Segurança, território e população. São Paulo: Martins Fontes; 2008.

${ }^{11}$ Vítimas do crack e também de preconceito e abusos sexuais. [Internet] Jornal O Tempo, 2 dez 2014. [citado nov 2017]. Disponível em: https://www.otempo.com.br/cidades/v\%C3\%ADtimas-do-crack-e-tamb\%C3\%A9m-de-preconceito-eabusos-sexuais-1.955332

${ }^{12}$ Secretaria Municipal de Saúde de Belo Horizonte. Of. GSMSA-ASS/SUS-BH/EXTERN/№ 76/2014 [Internet]. [citado nov 2017]. Disponível em: https://dequemeestebebe. wordpress.com/2017/04/15/reportagens-sobre-o-sequestro-debebes-2

${ }^{13}$ De quem é este bebê, Manifesto [Internet]. [citado nov 2017]. Disponível em: https:// dequemeestebebe.wordpress. com/2017/04/15/reportagens-sobre-o-sequestro-de-bebes-2/ 